$13^{\text {th }}$ International Conference on

AEROSPACE SCIENCES \& AVIATION TECHNOLOGY,

ASAT- 13, May 26 - 28, 2009, E-Mail: asat@mtc.edu.eg

Military Technical College, Kobry Elkobbah, Cairo, Egypt

Tel : +(202) $24025292-24036138$, Fax: +(202) 22621908

\title{
Managing Airports' Construction Projects, An Assessment of the Applicable Delivery Systems
}

\author{
Maged George Nassim*, Ehab Hanafi Mahmoud**
}

\begin{abstract}
Those involved in airport construction and similar large construction projects are aware that there are challenges to providing safe, quality projects that meet tight budgets with short time frames. Airport owners and operators, concessionaires and lessees, agency and governmental officials, design professionals and builders all have discussed, experienced, read, or overheard the challenges. Similarly, many have become aware of reports of the growing popularity of having multiple project delivery options available to them. This paper presents a list of the widely used project delivery systems (PDS) and offers guidance in selecting the most advantageous PDS. In addition, we look at the basic options of how project oversight (Project Management Options) can be provided. Project oversight addresses how the owner can manage the work; project delivery addresses the options for designing and constructing the project. This paper analyzes what conditions influence project success and discusses the types of project conditions for which each PDS is most applicable and offers the greatest potential to deliver a successful project.
\end{abstract}

Keywords: Airports, Construction Contracts, Construction management, Delivery systems.

\section{Introduction}

Among all the different types of transportation construction projects (Roads and tunnels, railway stations, ports and harbors ...etc.); an airport is a very unique, large, and complex organization that can mirror the size of a community when onsite employees are counted. Looking at the general plan of any big city we notice that the number of building types is so large in the housing sector, and decreases in a significant amount in transpiration sector and the minimum number is for the airports (some times null), while the cost is increasing rapidly in the opposite way (Fig. 1). An impressive and varied number of activities are performed at an airport, ranging from ground handling, to passenger handling, to commercial activities, to transports, etc., As part of airport operations, most of the activities are quite obvious to the average person; however, one aspect of an airport is usually overlooked - that is that airports not only need to manage air transport operations but also real estate investments and construction projects [2]. The question here is: Are the airport owners / or facilities professional responsible for the delivery of a capital projects able to use alternative project delivery methods? The ACI, ACC, \& AGC [1] suggested four distinct stops on the road of selecting and implementing the proper delivery system (Fig. 2). These four stops will be discussed in detail through this Paper.

\footnotetext{
*Egyptian Armed Forces, magud_g@hotmail.com

** Egyptian Armed Forces, ehabhmd@yahoo.co.uk
} 


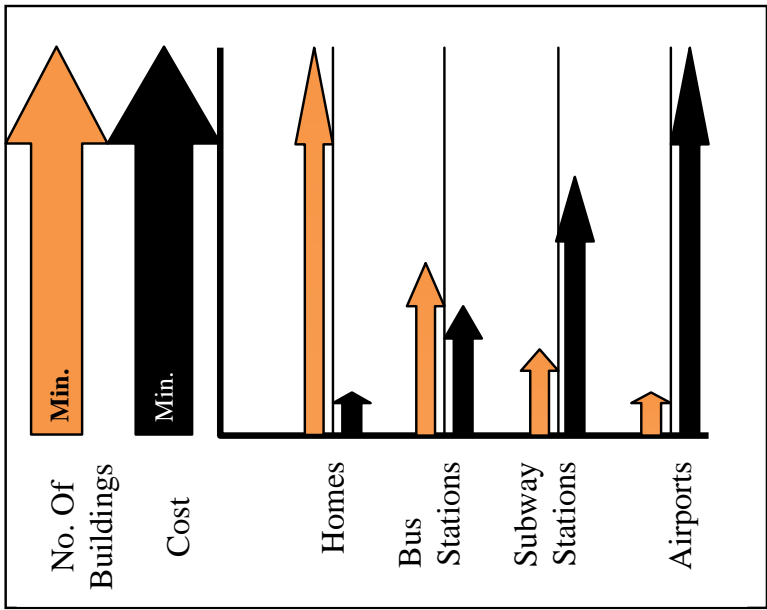

Fig. 1 Number of Building types versus cost in a big City

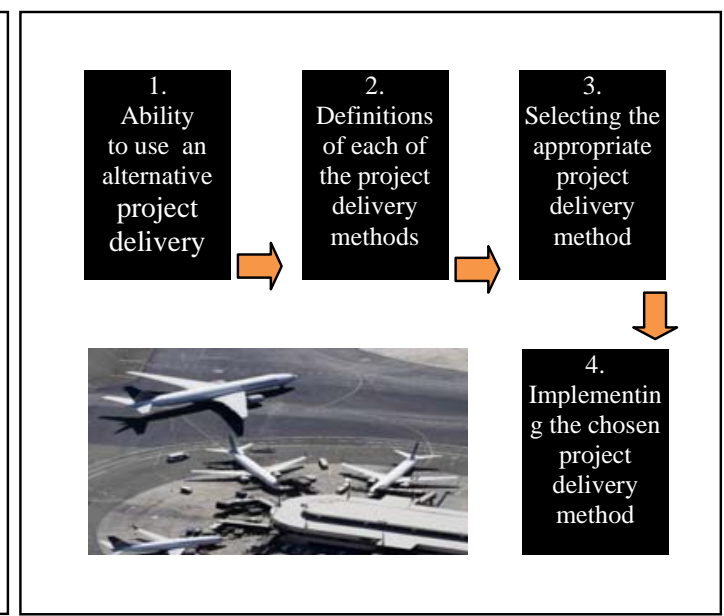

Fig. 2 The four stops on the road to Alternative project delivery

\section{Ability to Use Alternative Delivery Systems}

Only in recent year have publicly-owned airport had options other than design-bid-build for capital improvement projects. Legislation prompted by pressure from industry groups, a desire for change, project overruns and delays, and other factors have opened the door. Revisions to FAA [5], identifies principal changes to the professional services procurement process that added Alternative Delivery Methods to the Federal Aviation Administration's formalized acceptance of a variety of Project Delivery Systems (PDS). Experience has shown that most airport owners, who get to Stop 1, skip to Stop 3 and immediately start focusing on trying to select the most appropriate method. With the absence of any industry standard, there is confusion and inconsistencies throughout the industry. Eventually, however, all go back to Stop 2 to establish some definition of the delivery methods at least among their own organizations. The next section is focused on defining terms - Stop 2 - to ensure that all parties are speaking and understanding the same language. In addition, this includes some key information required for Stop 3, selection of the most appropriate method for each project to get an airport owner started in its planning and development.

\section{Delivery versus management}

Before defining the project delivery systems, it is important to distinguish between the delivery and management aspects of project delivery. Delivery refers to the method for assigning responsibility to an organization or an individual for providing design and construction services, while Management refers to the means for coordinating the process of design and construction (planning, staffing, organizing budgeting, scheduling, and monitoring) [4]. While this difference between management and delivery may appear subtle, it is nonetheless important to the understanding of the subject of project delivery systems. Project Management usually falls into one of two types:

\section{In-House}

In public or quasi-public organizations such as airports, in-house management could include resources from various agencies, or other parts of the airport, In-house options could include a variety of areas of expertise such as real estate, planning, design, engineering, construction or project management, or operations [9]. 


\section{Outsourced}

Common types of outsourced, third-party project management options include:

\section{Program Management (PM)}

Program Managers are typically involved in multiple projects or all phases of a single project Construction Managers as the airport's Agent (or adviser) is typically responsible for a single project and is primarily responsible for the design and construction phases on that project [4].

\section{Construction Manager as owner's Agent (CM)}

There is still quite a bit of confusion in the industry on the difference between a CM at-Risk versus a CM Agent. Based on the definitions offered here, CM at-Risk is a project delivery method and CM-Agency (or CM as adviser) is a form of project management [9].

\section{Defining Various Project Delivery Systems (PDS) and their Attributes}

This section provides a comparative overview of project delivery system approaches by describing those most widely used together with their primary attributes and strengths. In order to provide clear and unambiguous comparisons, we establish definitions for various project delivery systems and then describe the areas of commonality or difference among those systems. A project delivery system is defined as "the arrangement of relationships among the various parties involved in the design and risk" [4]; it establishes responsibility for how the project is delivered to the owner. While there exists a potentially infinite number of variations, most of the project delivery systems alternatives fall into one of the following three basic options:

- Design-Bid-Build (DBB)

- Construction Manger at Risk (CM@R)

- Design-Build (DB)

\section{Design-Bid-Build}

Often considered as the traditional approach, in the DBB project delivery system the project owner or developer hires a design professional to design the project. Upon completion of the design, the design professional prepares a single or multiple packages of construction documents with which to solicit competitive bids for construction. Fig. 3 is a schematic chart showing the relationships between the main parties of any construction project engaged in DBB system. Oftentimes the design professional's involvement on behalf of the owner continues during construction in the form of administering the construction contract, managing changes, and ensuring general conformance with contract documents [3].

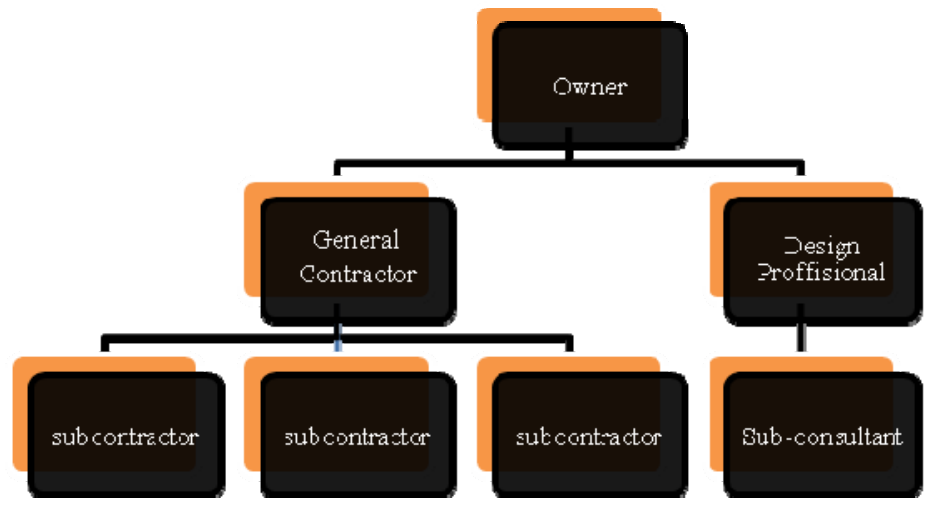

Fig. 3 Traditional design-bid-build relationship chart 
Attributes commonly associated with a DBB project delivery system are as follows:

- The owner holds contracts separately with a designer and a builder.

- The design and construction are sequential, i.e. the design is generally completed prior to construction bidding.

- Design changes are easily accommodated prior to start of construction.

- Little or no builder input in design, planning or value engineering (VE) is realized.

- Procurement begins with construction.

- Specifications are prescriptive.

- Significant owner involvement and decisions are required.

- While cost are predicted through the use of estimates during the design period, cost "surprises" - both good and bad - sometimes occur at the time of bid and award.

- Responsibility for project delivery is shared between the designer and the builder.

- The owner is responsible to the builder for design errors.

- The owner controls design and construction quality.

- Low bid cost and numerous qualified bidders ensure a high level of competition.

\section{Construction Manager at Risk (CM@R)}

As an alternate to DBB, many projects use a CM@R approach where the construction manager is engaged by the owner to be directly and completely responsible for the construction of the project. The timing of the CM@R's engagement, which occurs ideality relatively early in the design process has a large impact on his influence in the project [9].Under this arrangement, the CM@R, not the owner, holds the contracts for the construction subcontractors (Fig. 4), and so the CM@R is not only responsible for management of the construction, but also is at risk for the construction cost [3].

The additional attributes commonly associated with a CM@R system as compared to a traditional DBB approach include:

- Transfer of responsibility and significant risk from the owner to the CM@R for the entire construction effort, "performance risk", including subcontract administration and coordination, cost and schedule.

- The CM@R is responsible to each construction subcontractor for coordination, delay or impact on the overall construction effort.

- The owner remains responsible to the builder for design quality and errors

- The ability to gain the builder's input to design, phasing, logistics and value management decisions is increased.

- Daily Owner involvement, required resources and control over the construction effort are less.

- $\quad$ The CM effort may add cost.

\section{Design-Build (DB)}

The DB project delivery system differs from the DBB and CM@R approaches, as the project owner or developer hires a single entity to design and build the project instead of a separate designer and builder (Fig. 5). A design professional is no longer directly engaged by the owner as the "designer of record" but rather functions typically as a sub consultant to the DB entity [7]. Design-Builders can be selected with any of the three selection types, low bid, best value bid or qualifications based selections [1]. 
Attributes common to the DB project delivery system are as follows:

- The owner holds a single contract with the DB entity for the delivery of the entire project.

- The design and construction often have overlap where construction may begin before design is $100 \%$ complete, similar to a fast-tracked project.

- Procurement may begin prior to construction.

- Specifications are performance-based rather than prescriptive.

- A comprehensive and carefully prepared performance specification is required.

- Minimal daily Owner involvement, resources and decisions are required as compared to DBB and CM@R

- Design and construction quality are primarily controlled by the DB entity as the emphasis is on cost and schedule control.

- Dependent on contract conditions and form, costs are generally known once the DB contract is awarded, and usually, though not always, are fixed no later than the midpoint of design when the scope is firm.

- Transfer of responsibility and most risk from the owner to the DB entity for the entire design and construction effort.

- The ability of the builder to influence design, planning, phasing and value management are maximized.

- Number of qualified bidders and high bid cost may limit competition.

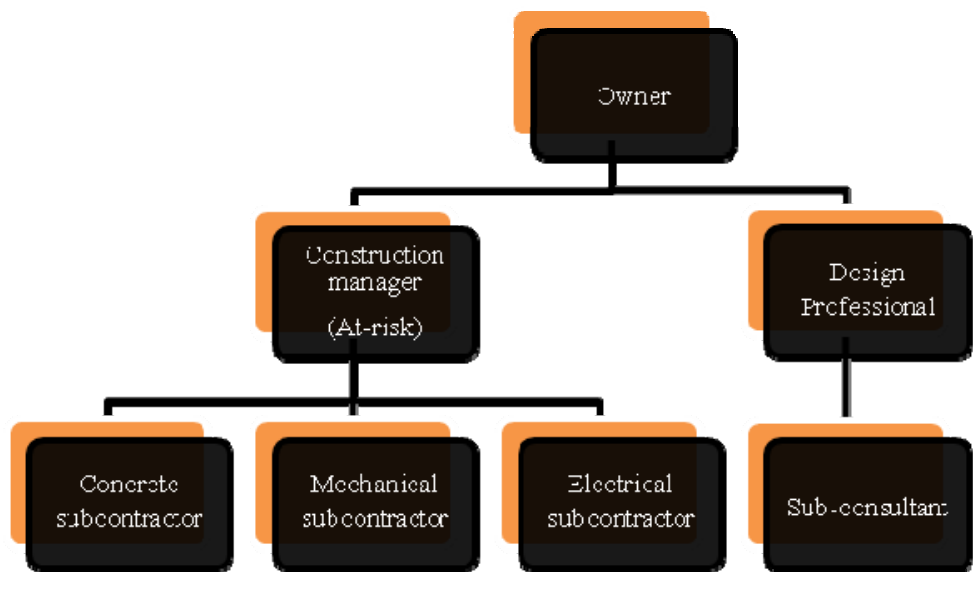

Fig. 4 Construction Manager At-risk relationship chart

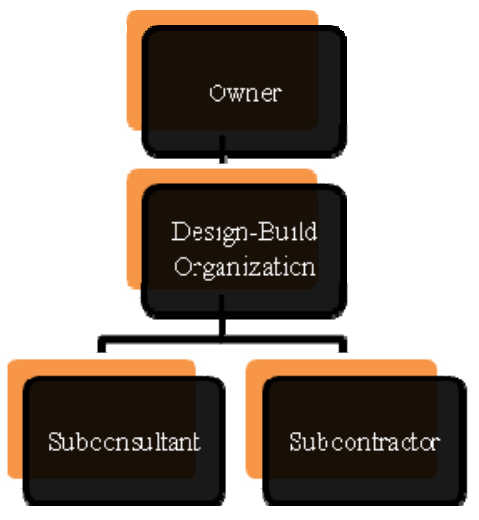

Fig. 5 Design-build relationship chart

\section{Preliminary comparison of the primary PDS}

Having described and defined the various PDS and their respective attributes, can be summarized for ease of comparison and then used as criteria for evaluation options. The comparison focuses on how each of the various project delivery systems addresses the owner's goals and objectives and other priorities. These general comparisons are presented graphically in the following charts (Fig. 6, Fig.7 \& Fig. 8). The illustrations on the charts present general trends of simple comparison from one extreme to another. Specific or detailed comparison is not intended by this presentation. 


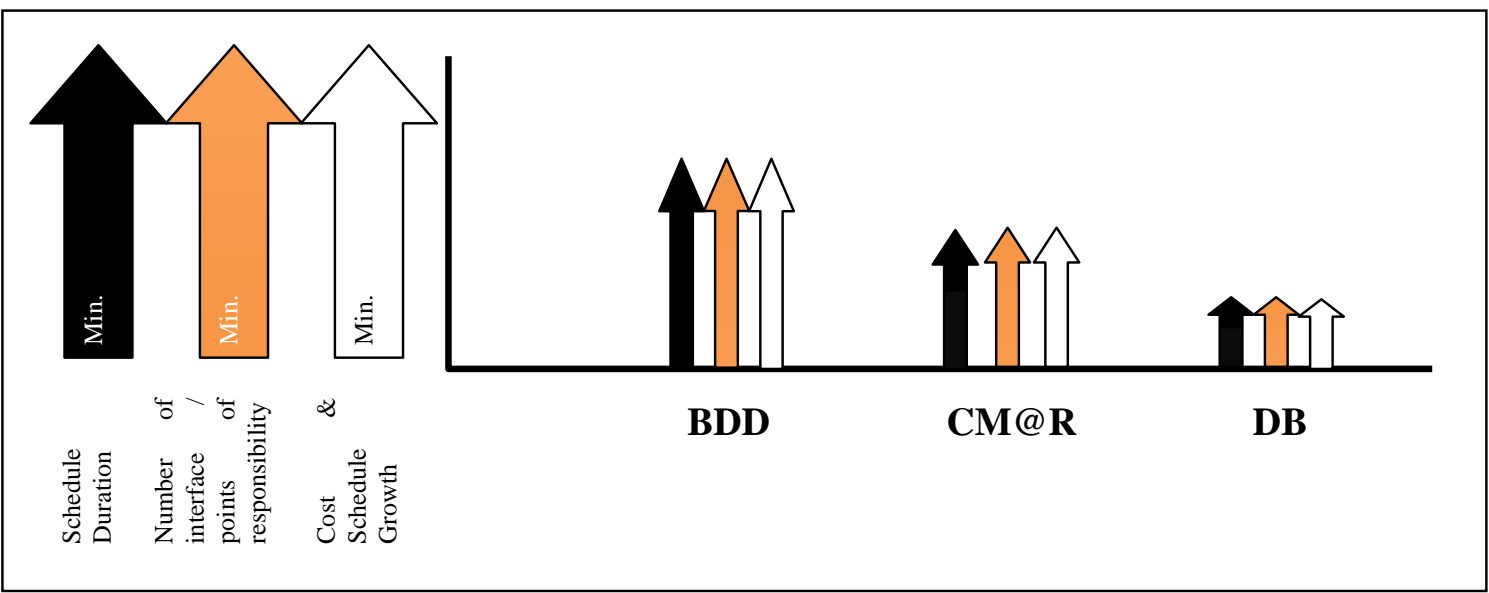

Fig. 6 Owner Risk profile

Owner Risk drops as it is shared with the construction team

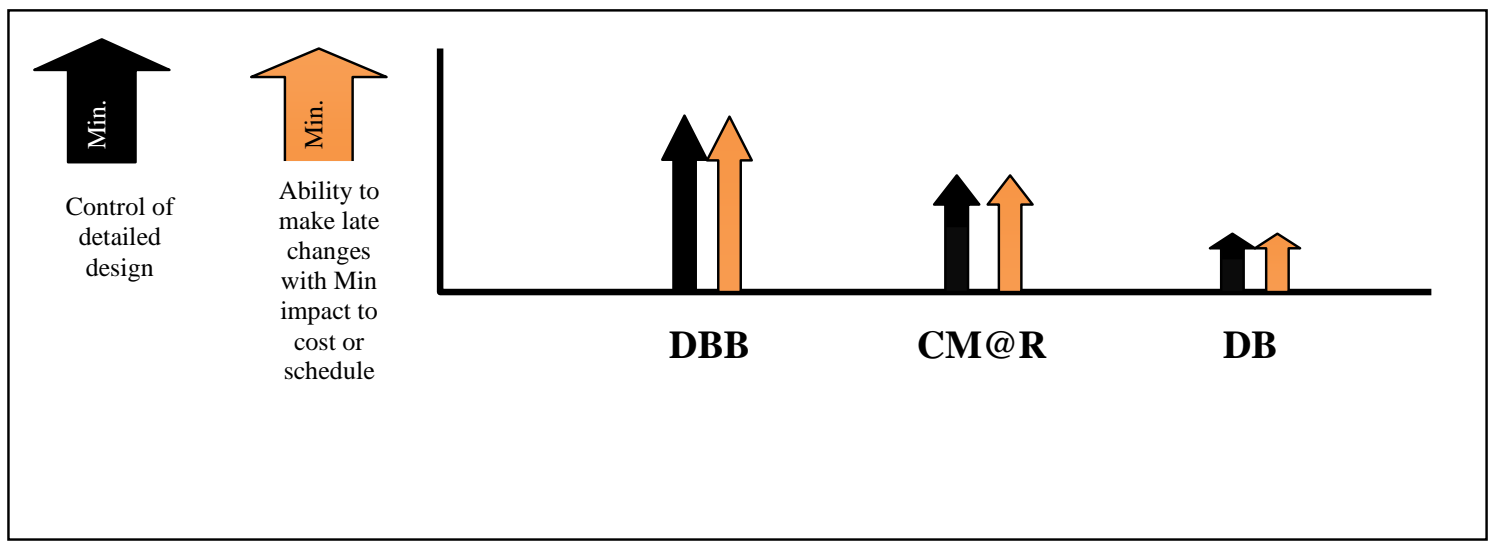

Fig. 7 Owner control profile

Owner relinquishes control over design and construction as it assigns risk

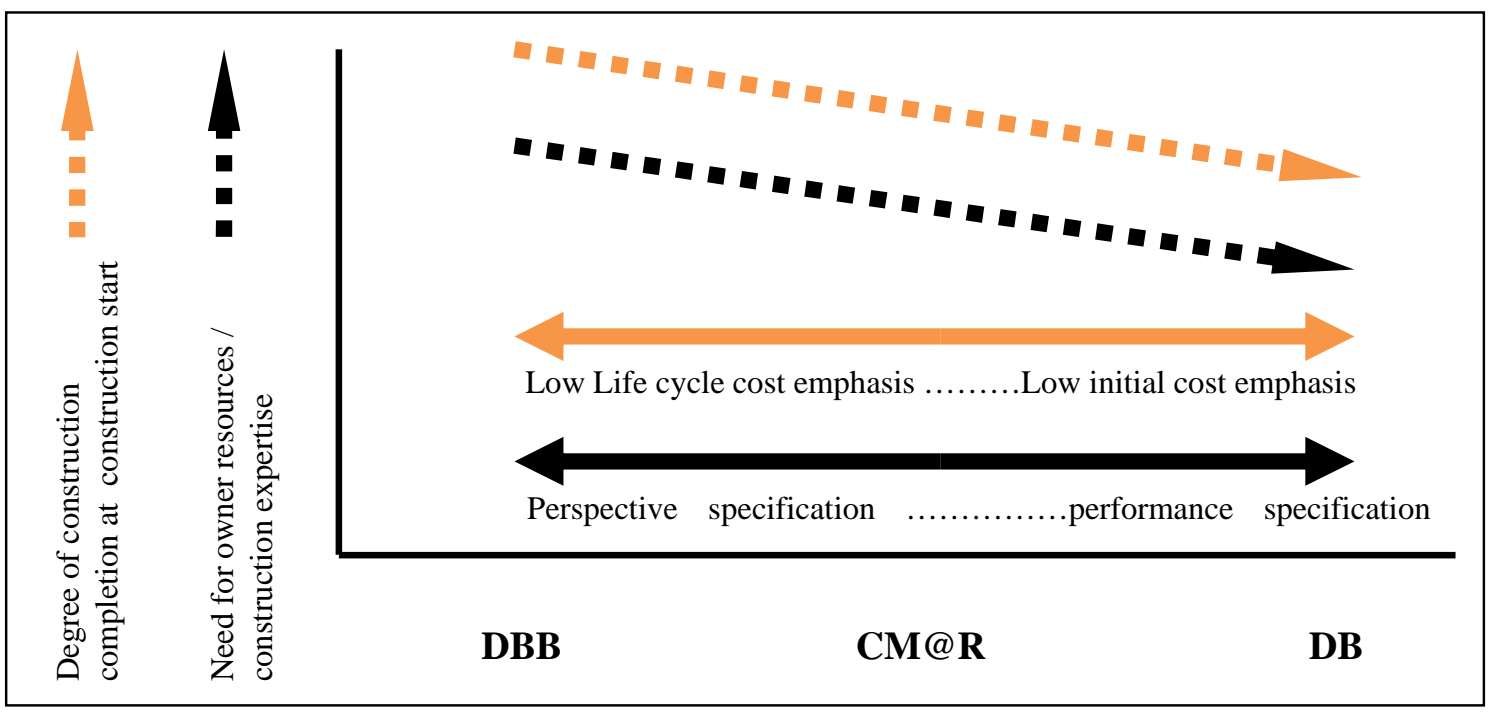

Fig. 8 Attribute Trends 


\section{Selecting the Appropriate Delivery Method}

The next "stop" for airport owners is to determine which delivery option is the most appropriate for a particular project. The airport owner should consider the major factors influencing the project in question and then consider the requirements of the project in the light of the unique characteristics of each of the various project delivery options. In selecting the appropriate delivery option, a thorough review of the potential risks and their allocation should be performed. Then, the airport owner should evaluate its ability and willingness to assume the risk inherent to the option selected [1]. To accomplish this, each of the relevant factors should be reviewed and considered. By the process of elimination, the most appropriate options can be determined. These major factors are divided into five categories as shown in Table 1.

Table 1 Major factors when selecting and appropriate delivery system

\begin{tabular}{|c|c|c|c|c|}
\hline $\begin{array}{c}\text { 1. Schedule / } \\
\text { necessity to } \\
\text { overlap phases }\end{array}$ & $\begin{array}{l}\text { 2. Ability to } \\
\text { define the } \\
\text { project } \\
\text { scope/potential } \\
\text { for changes }\end{array}$ & $\begin{array}{l}\text { 3. Owner's } \\
\text { internal } \\
\text { resources }\end{array}$ & $\begin{array}{l}\text { 4. Desire for a } \\
\text { single contract } \\
\text { or separate } \\
\text { contracts } \\
\end{array}$ & $\begin{array}{l}\text { 5.Regultory / } \\
\text { legal or funding } \\
\text { constraints }\end{array}$ \\
\hline $\begin{array}{l}\text { Tight project } \\
\text { milestones or } \\
\text { deadlines }\end{array}$ & $\begin{array}{l}\text { Scope definition } \\
\text { Potential for } \\
\text { changes during } \\
\text { construction } \\
\text { Need/desire for } \\
\text { the builder input } \\
\text { during design } \\
\text { Flexible to make } \\
\text { design changes } \\
\text { after } \\
\text { construction cost } \\
\text { commitment }\end{array}$ & $\begin{array}{l}\text { Ability or desire } \\
\text { to define and } \\
\text { verify program } \\
\text { \& design } \\
\text { content / quality } \\
\text { Experience with } \\
\text { the particular } \\
\text { delivery system } \\
\text { \& forms of } \\
\text { contracts } \\
\text { Ability to } \\
\text { participate in } \\
\text { multiple trade } \\
\text { builder / } \\
\text { supplier } \\
\text { evaluation } \\
\text { Desired } \\
\text { contractual } \\
\text { relationship and } \\
\text { ability to recoup } \\
\text { savings }\end{array}$ & $\begin{array}{l}\text { Ability or desire } \\
\text { to take } \\
\text { responsibility } \\
\text { for managing } \\
\text { the design } \\
\text { Ability or desire } \\
\text { to eliminate } \\
\text { responsibility } \\
\text { for disputes } \\
\text { between } \\
\text { designer and } \\
\text { builder / single } \\
\text { point } \\
\text { responsibility } \\
\\
\text { Local or small } \\
\text { business } \\
\text { participation }\end{array}$ & $\begin{array}{c}\text { Regulatory } \\
\text { statutory } \\
\text { requirements } \\
\text { Budget and } \\
\text { funding cycle } \\
\text { Multiple funding } \\
\text { sources }\end{array}$ \\
\hline
\end{tabular}

These Major Factors listed above are certainly not all that need to be considered, but addressing these key considerations will provide airport owners a guide for the selection of the most appropriate delivery option for each project. Furthermore, addressing these early in the project life cycle during pre-planning or pre-design will increase the chances for a successful project. Just selecting the "right" delivery option is not enough. There are numerous details to be addressed in the next step, implementation, in order to ensure the desired results are achieved. Requests for Proposals that clearly spell out expectations and 
match the right selection criteria with the right project delivery option are examples of the type of issues that must be addressed when implementing any project delivery option after one has been chosen.

\section{Suggestions for the Selection of PDS}

In selecting the appropriate PDS for a particular situation, the owner should have thoroughly considered the important factors just discussed and understand their relative priority in relation to project success. Adhering to the following suggested steps will assist owners in their endeavor to select the most suitable PDS to maximize project success.

- Identifying and defining what goals and objectives are most important to project success for its specific circumstances.

- Identifying and defining the special or unique issues that must be addressed.

- Recognizing the limits of resources and expertise of the owner organization.

- Selecting the PDS that most effectively can meet or achieve those requirements.

- Recognizing and acknowledging the trade-offs made in the selection of a PDS.

For example, in considering the use of $\mathrm{DB}$, the tendency is for an early construction start before design completion in order to shorten schedule. However, once construction begins, changes typically are more costly because they impact a design for which both procurement and construction are underway. The trade-off for the shorter schedule often achievable using DB is higher costs for any design changes that occur. Therefore, if DB is used, owners should freeze the design criteria as early as possible and avoid changes [3].

\section{Implementing the Chosen Project Delivery system}

Implementing the selected project delivery system requires the execution of many other stops, the following four stops are considered the most related and influencing factors on the success of that chosen PDS.

\section{Contract Types}

Regardless of the type of project delivery system selected, the contractual arrangement by which the parties are compensated also must be established. The basis for compensation is dependent and conditioned upon, and so must be consistent with, the project delivery system selected and its associated distribution of risk and responsibility between the owner and those delivering the finished project. The basis of compensation type relates to this financial arrangement among the parties, as to whether the designer or builder is to be compensated for their services at a set amount, i.e. Firm fixed price (lump sum), on a reimbursable basis up to a guaranteed maximum amount, on an incentive or award fee basis, or any number of variations of these general contract types [2]. The three primary or common types of compensation approaches include:

- Firm fixed price (lump sum) (FFP, LS)

- Reimbursable (cost plus) (CP)

- Guaranteed maximum price (GMP).

A firm fixed price or lump sum contract is an arrangement where the builder agrees to construct the defined scope of work for a set price. In this type of contract, the owner's risk 
of cost overrun is minimal. The builder has incentive to be efficient and lower cost because it can both be more cost competitive at bid time, and also can increase its own profit during construction. The owner does not share in the construction cost savings (unless the contract includes other incentive) [8]. At the other end of the spectrum, a reimbursable or cost plus contract is where a schedule or list of fees, unit prices, rates and markups are established under which the builder performs the work as requested and defined by the owner during the course of the project. The owner assumes the risk of cost overruns in the construction (excluding builder mistakes), the owner realizes any construction cost savings, and the builder is necessarily paid for any changes outside its control. In this contract type, the owner's risk of cost overrun is somewhat greater, however at least the cost for changes is somewhat controlled by the pre-established unit prices and rates. The builder has little incentive to be particularly efficient or save cost for the owner unless specific contract incentives are defined [8]. Between the firm fixed and reimbursable contract types is the guaranteed maximum price contract where the builder and owner agree on a target or maximum price for the construction [3].

\section{Contract Language}

The purpose of the formal Contract is the memorialize the agreement of the parties regarding the selected project delivery system approach, the allocation of work scope, responsibilities, and risk, the arrangements for financial compensation, and similar aspects of the project [1]. Often by definition within the basic document, a Contract typically includes several separate documents including a basic agreement of general terms and conditions, additional or special conditions unique to the project, and the terms for payment, PLUS all other supporting documents necessary to further define the nature and extent of work such as the schedule, the drawings, specifications and any other technical requirements for the work. Furthermore, all parties need recognize that disputes over scope, quality and other issues may still arise, particularly in today's complex fast-paced projects. Consequently, it is important that the Contract define how such disputes will be handled in a manner to minimize disruption and cost/schedule impact to the project [3].

\section{Management Execution}

In short, it refers to how the owner carries out his responsibilities as compared to how the design and construction firms carry out their collective responsibilities. The owner needs to review the selection criteria that drove the choice of project delivery system and effectively communicate to his various team members the goals, objectives and issues that drove the selection of project delivery system. Also the owner needs to define any review and approval processes, the turnover and acceptance process, handoffs and transitions of responsibility, and similar interfaces [1].

\section{Financing}

The application of delivery system should include consideration of its funding source. There is a broad spectrum of financing options for airports, and more options evolve as needs and opportunities arise, typically, airports have relied on four primary sources of financing: Governmental assistance, passenger facility charges, bond sales, and capital expenditure of airport revenue [10]. 


\section{Conclusion}

It was found that more than one system could be applied in delivering the construction projects of airports; this trend was a result of many factors including pressures from industry groups, a desire for change, project overruns and delays and many others. Because there is no one unique definition for each project delivery system, it was important to define each of the most widely used systems before the discussion and comparison between the commonly associated attributes to each of them. Observing the comparison charts indicated that schedule duration, cost and schedule growth, owner's risk, and number of interfaces all decrease from the DBB passing by the CM@R to the minimum at DB. Owner's control of design, quality, and ability to make design changes with a minimum impact to cost and schedule also decreases when moving from DBB to DB. When selecting the appropriate PDS the owner should consider the major factors influencing his project and its requirements in the light of the unique characteristics of each of the various project delivery systems. Implementing the selected PDS requires a proper selection of the contract type and language, management execution, and choosing the suitable financing method, and above all proposals that spell out expectations and match the right selection criteria with the right PDS.

\section{References}

[1] ACI-NA, ACC, \& AGC joint committee, Airport's Owner's Guide to Project Delivery Systems, Airports council international-NA, Airport Consultants Council,\& Associated General Contractors of America, 2006.

[2] Adrem, A., et al, Managing airports construction projects, Booz Allen \& Hamilton Inc., 2006

[3] Bennett, F. Lawrence, The Management of Construction, a Project Life Cycle Approach, Butterworth-Heinemann, UK, 2003.

[4] Dorsey, R.W., Project delivery systems for building construction, Associated general contractors of America, 1997.

[5] FAA, Architectural engineering and planning consultant services for airport grant projects, Federal Aviation Administration Advisory Circular 150/5100-14D, 2005.

[6] FAA, Innovation finance and alternative sources of revenue for airports, Transportation research board, 2007.

[7] Ling, F.Y.Y. and Poh, P.H.M., Problems encountered by owners of design-build projects in Singapore, International Journal of Project Management Vol. (26), 164173.,2008.

[8] Schuette, S.D. and Liska, R.W., Building construction estimating, McGraw-Hill, USA, 2004.

[9] Trauner consulting services, Inc., Construction project delivery systems and procurement practices, 2007.

[10] Wells, A. T., ED.D., and Toung Seth, Airport planning and management, McGraw-Hill, 2004. 